\title{
Mercado Brasileiro de Lácteos: análise do impacto de políticas de estímulo à produção ${ }^{1}$
}

\author{
Bruna Márcia Machado Moraes² e Reisoli Bender Filho ${ }^{3}$
}

\begin{abstract}
Resumo: O trabalho objetivou avaliar os potenciais impactos de políticas de incentivo à produção de leite e derivados nas regiões brasileiras a partir da simulação de duas políticas: a primeira consistiu em aumentos de $10 \%$ e $20 \%$ na concessão de subsídios à produção de leite e derivados (cenários 1A e 1B), e a segunda, de reduções de $10 \%$ e $20 \%$ nos impostos incididos na produção de leite e derivados (cenários $2 \mathrm{~A}$ e 2B). Ambas as simulações foram realizadas tendo como base o Programa de Equilíbrio Geral da Economia Brasileira (Paeg). Os resultados indicaram que as regiões brasileiras com maior produção de leite, respectivamente Sudeste, Sul e Centro-Oeste, seriam as mais beneficiadas, além de deslocar fatores produtivos, caso do capital e do trabalho, das regiões Norte e Nordeste, cujo setor lácteo apresentaria perdas. Estes resultados foram evidenciados em maior magnitude quando simulada a política de ampliação da concessão de subsídios comparativamente à política de desoneração fiscal. A partir disso, a implementação de políticas regionais e setoriais diferenciadas faz-se alternativa indicada.
\end{abstract}

Palavras-chaves: produção de leite, incentivos à produção, regiões brasileiras, equilíbrio geral.

Abstract: The study aimed to assess the impact of incentive policies for the production of milk and
dairy products in the Brazilian regions from the simulation of two policies: the first consisted of
increases of $10 \%$ and $20 \%$ in subsidies for the production of milk and dairy products ( $1 \mathrm{~A}$ and $1 B$
scenarios), and the second, a reduction of $10 \%$ to $20 \%$ in taxes on the use of primary factors in
the production milk and dairy products (scenarios $2 \mathrm{~A}$ and $2 B$ ). Both simulations were performed
based on the o General Equilibrium Analysis Project of the Brazilian Economy (Paeg). The results
indicated that the Brazilian regions with higher milk production, respectively Southeast, South and
Central-West would be the most benefited, as well as displace the production factors such as capital
and labor, from the North and Northeastern regions, whose dairy sector would present losses. These

1. Data de submissão: 13 de julho de 2016. Data de aceite: 21 de julho de 2017.

2. Universidade Federal de Santa Maria. Santa Maria, Rio Grande do Sul, Brasil. E-mail: brunammmoraes@hotmail.com

3. Universidade Federal de Santa Maria. Santa Maria, Rio Grande do Sul, Brasil. E-mail: reisolibender@yahoo.com.br 
results were shown in greater magnitude when simulated the policy of expansion of subsidies compared to the tax relief policy. From this, the implementation of differentiated regional and sectorial policies is the alternative indicated.

Key-words: milk production, production incentives, Brazilian regions, general equilibrium.

Classificação JEL: C6, C68.

DOI: http://dx.doi.org/10.1590/1234-56781806-94790550410

\section{Introdução}

A produção leiteira no Brasil deixou de ser realizada, em grande parte, para subsistência, e passou a ser utilizada como fonte de renda a partir da década de 1950, momento em que estava ocorrendo o início do processo de industrialização do País. Nas quatro décadas seguintes, até 1990, o comércio de leite cru foi regulamentado pelas agências governamentais e os preços praticados eram os mesmos em todas as regiões do Brasil (BORTOLETO e WILKINSON, 2000).

Em termos produtivos, a estrutura era organizada, quase que exclusivamente, por cooperativas especializadas apenas no comércio de leite in natura. Já a produção de derivados, embora em pequena quantidade, era realizada por algumas empresas multinacionais que dominavam os segmentos de produtos lácteos. Mudanças mais expressivas no mercado lácteo ocorreram nos anos seguintes, a partir de 1990, em um ambiente de abertura econômica e comercial, com a inserção de duas multinacionais (Parmalat e Danone) no mercado doméstico e o surgimento de novos modelos de processamento de leite in natura e novos derivados (JANK, 1999).

Embora em crescimento, a pecuária leiteria enfrentou momentos distintos na década de 2000 , sendo que, nos anos 2001/2002, o setor lácteo passou por uma crise desencadeada pela forte baixa nos preços recebidos pelos produtores. Por este motivo, vários deixaram a atividade e, em consequência, a produção diminuiu. Porém, com a desvalorização da moeda doméstica e a crise láctea da Argentina (principal parceira comercial do setor), o Brasil aumentou em 121,5\% as exportações do setor, e mesmo assim continuou apresentando déficit na balança comercial de lácteos, já que a produção teve alterações devido aos preços praticados (CEPEA, 2003).

Esta situação de dependência de importação de produtos lácteos se acentuou ao longo dos anos recentes, sobremaneira depois de 2009, devido à isenção de tarifas de comércio e a carga tributária favorável da Argentina e do Uruguai, países membros do Mercosul e, também, os principais exportadores de leite para o Brasil. Esta política determinou que o leite originário destes mercados e seus derivados chegasse ao Brasil com preços mais competitivos que o produzido domesticamente. Logo, este aumento de competitividade dos produtos lácteos advindos do Mercosul ligado à deficiência de suprir a demanda por produtos de setor fez com que houvesse um aumento nas importações nos anos recentes (CEPEA, 2009).

Apesar desse cenário, a produção de leite e derivados vem crescendo, assim como a demanda pelos produtos do setor que tem aumentando junto à renda dos consumidores, os quais, com maior poder aquisitivo, tendem a incluir produtos com maior valor nutricional em sua cesta de consumo diário (DIEESE, 2014). A procura por esses produtos vem aumentando devido à preocupação da sociedade com a alimentação mais nutritiva e saudável.

Porém, o crescimento não tem sido suficiente, apesar de receber estímulos financeiros, por meio de empréstimos e financiamentos, a produção láctea necessita de políticas de incentivos para que possa 
expandir o volume produzido. Logo, para que a atividade leiteira se consolide há a necessidade de uma política de incentivos à produção, caso dos custos de produção e da carga tributária, conforme destacado pela Empresa Brasileira de Pesquisa Agropecuária - Embrapa (2014). Neste sentido, o Ministério da Agricultura, Planejamento e Abastecimento (Mapa), em 2014, com o objetivo de incentivar a produção, criou o Programa Mais Leite, cuja projeção é que, em 2023, o País possa suprir a demanda do mercado interno e ainda exportar o produto, consolidando o Brasil no mercado internacional de lácteos.

A despeito dos recentes programas, a produção brasileira, em termos regionais, ainda é caracterizada pela elevada heterogeneidade, tanto em termos de mercado (produção, preços e consumo) quanto em termos de produtividade (formas de produção), o que dificulta em parte o atingimento dos objetivos para o setor. A região Sudeste, principal produtora, é responsável por cerca de 39\% do total de leite produzido no País, seguida pela região Sul, cuja produção atinge cerca de $29 \%$. Com participação menor estão as regiões Norte (6\%), Nordeste (11\%) e Centro-Oeste (15\%). Além disto, essas três regiões possuem produtividade mais baixa quando comparada às outras duas, mesmo apresentando um rebanho significativo, como é o caso da região Nordeste (IBGE, 2015).

Todavia, a intervenção por meio de políticas tarifárias e de subsídios ainda é um tema incipiente e complexo, como também as ações e medidas para o referido crescimento, que ainda são pouco conhecidas e difundidas. Neste sentido, identificar impactos de políticas de incentivos à produção em determinado setor, caso específico do lácteo, não é tarefa fácil. A partir desta discussão, o artigo tem como objetivo avaliar os impactos sobre os volumes produzidos de leite nas regiões brasileiras a partir de políticas de estímulo à produção.

Nesta linha, a concessão de subsídios à produção de leite e derivados tem ganhado destaque também nas discussões da Organização Mundial de Comércio (OMC). Segundo Lima, Lucca e Trennepohl (2014), países como Estados Unidos, União Europeia, Austrália e Nova Zelândia estão destinando elevados volumes de subsídios financeiros para viabilizar a produção de leite e derivados. Por ter grande importância nestes países, a produção de leite e derivados alcançou níveis elevados de sofisticação na estrutura produtiva, com destaque para políticas de apoio e proteção aos produtores rurais.
Para discutir tais questões, além desta introdução, o trabalho está estruturado em mais quatro seções. $\mathrm{Na}$ seção dois estão expostas as mudanças ocorridas no mercado de lácteos ao longo do tempo, seguido dos aspectos metodológicos utilizados. Na quarta seção são discutidos os resultados e, por fim, as considerações finais.

\section{Mercado brasileiro do leite}

\subsection{Mudanças estruturais: evolução do mercado e políticas de incentivo}

A evolução na produção e comercialização observada ao longo dos anos gerou um conjunto de determinantes à transformação do mercado lácteo brasileiro. Um deles está ligado à abertura comercial e a integração econômica, a valorização cambial e também a profissionalização da produção. Outro e, talvez o mais importante, relaciona-se à mudança nos padrões de consumo de lácteos da população brasileira. Associado a esse está a transformação do produto em commodity e a constituição de grandes estruturas industriais (CORREA, 2014).

Entretanto, a produção de leite é realizada de diferentes formas, mesmo porque, por um lado, existem sistemas com alto nível tecnológico, elevada qualidade genética do rebanho e condições modernas de suplementação alimentar; enquanto que por outro, devido ao crescimento da agricultura familiar, o sistema produtivo se desenvolve de forma menos qualificada, com padrões genéticos menos aprimorados e com a produção sendo destinada para o mercado informal (BORGES et al., 2014).

Embora a produção e o consumo tenham crescido em níveis praticamente similares ao longo dos últimos anos, ressalta-se que o leite produzido domesticamente também serve de matéria prima à produção de todos os derivados. Logo, para essa produção faz-se necessário quantidades proporcionalmente maiores de litros, além das quantidades adquiridas in natura pelos consumidores.

Neste cenário, o Brasil acentuou a dependência de importações, sendo o excedente originado do Mercosul $^{4}$, principalmente da Argentina, do Uruguai e

4. Acordo firmado pelos principais países da América do Sul, que conta com importantes alterações nas barreiras de comércio, facilitando o comércio de vários bem e serviços entre eles (ver BUENO, MARTINS e MARGARIDO, 2005). 
do Chile, cuja participação no total importado foi de cerca de $81 \%$ entre 1998 e 2014 . Estes fluxos comerciais foram aprofundados em decorrência da diminuição de tarifas resultante do acordo, que fez com que o comércio de leite oriundo do bloco chegasse com um preço mais competitivo ao Brasil, em comparação ao leite da União Europeia, dos Estados Unidos e de outros países importantes produtores do produto.

Associado a esses fatores, domesticamente o mercado de produtos lácteos tem uma estrutura bastante complexa, visto que há um elevado número de agentes atuando no setor. Se, por um lado, existem produtores e captadores, que são os agentes responsáveis pelo produto chegar até as indústrias beneficiadoras. Por outro, estão às indústrias responsáveis por fornecer o leite e seus derivados para os canais de distribuição.

Com o crescimento do setor lácteo e a nova configuração produtiva e comercial, o Ministério de Agricultura, Planejamento e Abastecimento (2002) lançou programas de incentivo à produção de leite. Entre eles estão os programas de pagamento por qualidade e as normativas que indicam valores nutricionais a serem seguidos. Normativas essas utilizadas como base para elaborar o pagamento por litro de leite de cada produtor em específico. Além disso, existe o Programa Mais Leite, desenvolvido pelo Mapa, cujo objetivo é de aumentar a produção leiteira em $40 \%$ no período de dez anos.

A despeito destes programas, existem outros fatores que atuam de forma contrária, desestimulando a produção de leite. Caso das altas taxas de juros cobradas pelas agências concessoras de crédito e a elevada carga tributária, fatores que fazem com que os insumos agrícolas cheguem ao produtor com um preço menos competitivo, deixando a atividade com pouca lucratividade e com um custo de produção majorado (CEPEA, 2014).

Em geral, as formas de incentivos existentes no Brasil relacionam-se à normatização da produção no quesito qualidade, sendo que ao longo dos anos foram criados vários programas de pagamentos, onde o leite de qualidade tem sido bonificado. Além destes, há outros órgãos, como a Empresa Brasileira de Pesquisas Agropecuárias (Embrapa), a Empresa de Assistência Técnica de Extensão Rural (Emater), além daqueles em termos de estado, que atuam de forma a auxiliar os produtores a identificar novas formas de manejo para facilitar a produção na atividade leiteira.
Com essa temática, foram identificados trabalhos que discutem o mercado de produtos lácteos e ainda os que analisam os elos que participam deste setor. Porém, os trabalhos restringem-se a identificar os desequilíbrios entre oferta e demanda neste mercado, como também os impactos de alterações na carga tributária, que se mostrou relevante para as indústrias e produtores. Entretanto, os determinantes da produção no setor de lácteos brasileiro não foram abordados, tampouco quais fatores mais impactariam na expansão do setor, aspectos que justificam a proposta central deste estudo.

Para isso, os cenários que foram simulados para subsidiar a discussão acerca dos potenciais impactos de incentivos à produção do setor de produtos lácteos brasileiro têm como base duas linhas de políticas, tanto internas como externas/comerciais, que são: subsídios internos de produção e impostos ao uso de fatores primários $^{5}$ na produção. Estas duas diretrizes foram definidas pelo fato de que influenciam financeiramente na atividade leiteira e agrícola como um todo. No que tange aos subsídios internos de produção, estes auxiliam na redução do custo de produção, pois servem de incentivos à atividade. Porém, ressalta-se que, no Brasil, os subsídios à produção leiteira são oferecidos na forma de financiamentos concedidos pelas agências de fomento à agricultura, além de apoio técnico especializado fornecido por empresas públicas.

\subsection{Produção, consumo e preços de leite nas regiões brasileiras}

O setor brasileiro de lácteos vem passando por várias alterações desde a década de 1990, isso se deve principalmente à desregulamentação do mercado ocorrida a partir deste período. Após o fim da intervenção estatal, em 1972, observou-se maior competitividade entre as empresas captadoras que atuavam no setor, induzindo os produtores a buscar a profissionalização na produção de leite (TESSARO, TORRES e BULHÕES, 2008). Outro aspecto no processo de diversificação dos produtos derivados de leite foi a demanda das multinacionais que já atuavam no mercado, resultando em um necessário aumento na produção, já que as empre-

5. Termo utilizado pelo Paeg (Programa de Equilíbrio Geral da Economia Brasileira) como parâmetro para os impostos incididos sobre a produção em todos os setores da economia. 
sas necessitavam de mais matéria prima à produção dos derivados. Com isso, os produtores começaram a ofertar mais leite in natura, já que a demanda estava aquecida (MENDES, PEREIRA e TEIXEIRA, 2011).

Em meio a este ambiente favorável, cada região do Brasil desenvolveu a atividade leiteira de forma diferente, umas com mais intensidade tecnológica e outras como sendo apenas uma atividade para subsistência. Ressalta-se que, em todas as regiões, a cadeia encontra-se estruturada, com produção, industrialização e comercialização, gerando renda e distribuindo alimentos oriundos da pecuária leiteira (GOMES, 1995). Cenário que pode ser visto na evolução da produção de leite cru (ou in natura) e adquirido pelas empresas beneficiadoras nas diferentes regiões brasileiras entre 1998 e 2014 (ver Figura 1). Os quantitativos apresentados traduzem apenas a produção formal de leite, sem contar com o que é produzido e comercializado pelos próprios produtores, sem passar por nenhum processo de beneficiamento.

A região Sudeste possui a maior representatividade na produção brasileira de leite, com aproximadamente $39 \%$ do total de litros produzido no período em análise. Embora apresente o maior montante de leite in natura comercializado e a maior representatividade quanto ao número de vacas ordenhadas (35\%), a região tem só o segundo maior índice de produtividade por animal ordenhado, com aproximadamente 1.333 litros/ano, segundo IBGE (2014). Em termos de preço médio, a região comercializou levemente acima da média nacional de R\$ 1,05/litro, em 2015, caso do estado de Minas Gerais (R\$ 1,08/1) e de São Paulo (R\$ 1,07/l), segundo Cepea/Leite (2015).
Da mesma forma, a região Sul produz volume representativo de leite in natura, cerca de $29 \%$ do total, além de apresentar a maior produtividade de leite 2.057 vacas/litros/ano. Esta região é responsável por empregar cerca de $11 \%$ dos trabalhadores rurais, participação inferior a produção, o que caracteriza a produção como de alto nível tecnológico. Com relação aos preços recebidos, a região sul apresentou preços abaixo da média nacional, sendo pagos R $\$$,98 centavos por litro (CEPEA/LEITE, 2015). Embora com preços inferiores, o consumo aparente de leite in natura apresentou tendência de queda do início do período até 2008, quando inverteu o comportamento; contudo, em 2014, o consumo ficou 76\% menor comparativamente ao de 1998.

Como o Brasil apresenta mercados dinâmicos e demograficamente diferentes para o leite in natura, nas regiões Sul e Sudeste esse produto tem demanda menor por haver grande número de empresas beneficiadoras produzindo uma variedade maior de derivados (leite em pó, sem lactose, iogurtes, entre outros), conforme a Sociedade Nacional de Agricultura (2015). Outra característica está no fato de a atividade leiteira ser realizada, em grande parte, em propriedades de pequeno porte, além de possuir um número expressivo delas caracterizadas como de agricultura familiar, com proximidade umas das outras, facilitando a captação por parte das empresas (TRICHES, 2011).

A região seguinte em termos de produção é a Centro-Oeste, que ao longo do período analisado, apresentou participação média de cerca de $15 \%$ do total de leite produzido. Com relação aos preços pagos por litro de leite in natura, o valor praticado no estado de Goiás manteve-se acima da média nacional, com

Figura 1. Quantidade de leite cru refrigerado produzido e comercializado pelos produtores nas macrorregiões brasileiras (em 1.000 litros)

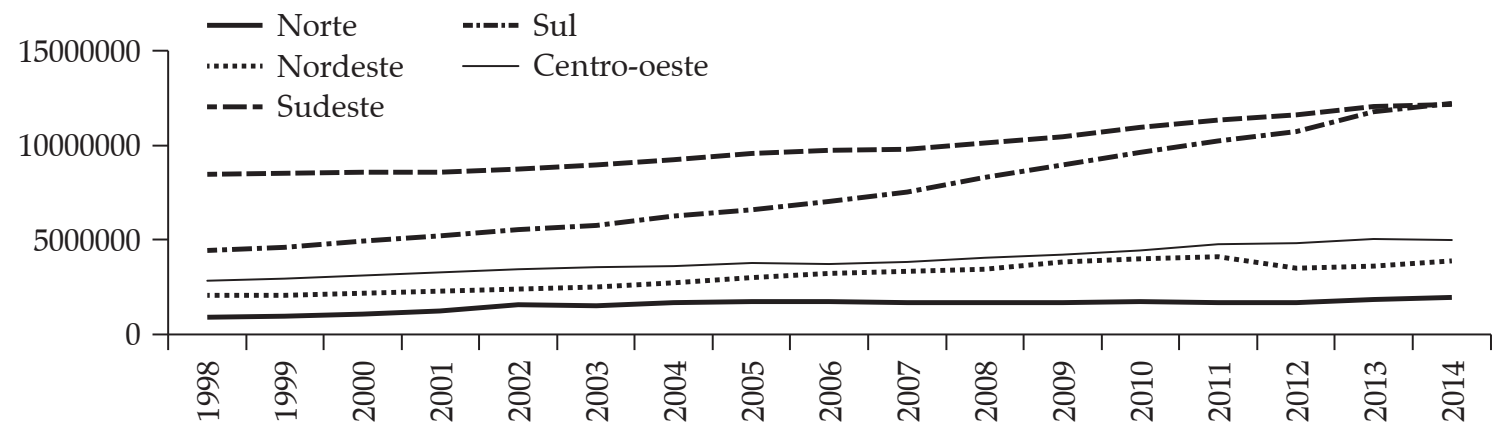

Fonte: Elaborado pelos autores a partir de dados do IBGE (2014). 
valor de R\$ 1,06 por litro comercializado (CEPEA/ LEITE, 2015). Além disto, a participação do mercado de trabalho ficou em torno de $11 \%$ dos trabalhadores rurais empregados na atividade leiteira (DIEESE, 2014). Embora a região seja responsável por importante volume de produção, o consumo apresentou comportamento instável ao longo do período. Mesmo que no ano de 2014 a região tenha demandado mais de 4,9 milhões de litros de leite in natura, o consumo foi $43 \%$ superior ao encontrado em 2000 e, desde 2010 a demanda tem apresentado retração.

Com uma participação menos expressiva, a região Nordeste é responsável por cerca de $11 \%$ da produção nacional de leite in natura. Embora apresente rebanho de aproximadamente $20 \%$ do total de vacas ordenhadas e também a maior concentração de trabalhadores rurais do País, cerca de um terço, a produtividade média é baixa quando comparado às outras regiões - 725 litros/ vaca/ano, segundo IBGE (2015). Com relação ao consumo de leite in natura, a partir dos anos 2000 verifica-se estabilidade no volume consumido, ficando em torno de 4,6 milhões de litros em 2014; contudo, caracteriza-se como importadora líquida de produtos lácteos.

Por fim, na região Norte, encontra-se produção equivalente a $6 \%$ do total e cerca de $9 \%$ dos trabalhadores do setor agrícola (DIEESE, 2014). Por apresentar proporção relativamente baixa de trabalhadores, quando comparada à extensão territorial, a região apresenta predominância de técnicas intensivas em mão de obra. Embora a região tenha baixo nível de produção de leite in natura, o consumo aparente tem aumentado, sendo que, entre 1988 e 2014, a demanda por leite in natura foi cerca de 90\% maior, aproximando-se dos 2 milhões de litros em 2014. Este aumento se deve, principalmente, pelo incremento na renda oriundo dos programas de transferência de renda do governo federal, bem como de programas de distribuição de alimentos produzidos pela agricultura familiar nas escolas, caso do Programa de Aquisição De Alimentos - PAA (Sociedade Nacional de Agricultura, 2015).

\section{Aspectos metodológicos}

\subsection{Modelo Paeg}

Para atingir os objetivos propostos, de analisar os potenciais impactos de uma política de incentivos à produção leiteira no Brasil, foi utilizado um modelo de equilíbrio geral multirregional e estático. A operacionalização deu-se pela utilização do Projeto de Análise de Equilíbrio Geral da Economia Brasileira (Paeg), na sua versão 3.0, elaborado por Teixeira et al. (2008) - base que contempla as cinco regiões brasileiras e os principais parceiros internacionais do País. Com isso, se torna possível analisar os fluxos comerciais internos e externos, bem como mudanças em variáveis políticas e comerciais.

Como base para sua formulação, o Paeg utiliza a estrutura básica do modelo Global Trade Analysis Project (GTAP), elaborado por Hertel (1997), porém, sendo operacionalizado no GTAPinGAMS (versão 8.0 do GTAP), conforme elaborado em Rutherford e Paltsev (2000) e Rutherford (2005). Especificamente do GTAP o modelo utiliza a base de dados, enquanto a formulação é definida a partir de um problema de complementariedade não linear, sendo necessária a operacionalização por meio de linguagem de programação GAMS (General Algebraic Modeling System), conforme encontrado em Brooke et al. (1988).

Nesta linguagem, o modelo GTAP é resolvido como um sistema de equações linearizadas e permite que o modelo seja operacionalizado como um problema de complementariedade não linear em linguagem GAMS. O Paeg utiliza a mesma forma de programação do MPSGE (Modeling Programing System for General Equilibrium), proposto e desenvolvido por Rutherford (1999), funcionando por meio de blocos de funções de produção, de demanda e de restrições específicas. Desta forma, o MPSGE transforma as informações contidas nos blocos econômicos em equações algébricas que são processadas pelo GAMS.

O modelo Paeg caracteriza-se por ser estático, multissetorial e multirregional, sendo que cada região possui uma matriz insumo-produto que representa a produção e a distribuição de bens e serviços. Nele, o Brasil está desagregado nas cinco grandes regiões em que se compõe. Além disso, o modelo está baseado na otimização em que os consumidores, tanto final quanto intermediários, buscam a maximização de seu bem-estar, dada sua restrição orçamentária. Ressalta-se que, pelo fato de o modelo ser estático, os níveis de investimento e produção do setor público são igualmente estático. O primeiro levantamento das matrizes insumo-produto das cinco regiões brasileiras foi realizado por Parré (2000), sendo que, para a versão Paeg 3.0, foi realizada a atualização para o ano de 2007, cujo 
objetivo foi a padronização com o GTAP, que também tem sua última versão divulgada nesse mesmo ano.

Um conjunto de identidades que deve ser respeitado à execução do modelo está ligado aos lucros operacionais líquidos em todos os setores da economia. Porém, o Paeg, assim como o GTAP considera que o mercado em análise segue as regras de competição perfeita e também mantém retornos constantes à escala. Neste caso, o valor da produção deve ser igual aos custos com insumos intermediários e fatores de produção, de modo que os lucros econômicos devem ser iguais a zero (ver GURGEL, PEREIRA e TEIXEIRA, 2014).

Essas identidades devem ser observadas em todos os setores produtivos e atividades econômicas existentes, as quais estão definidas nas Equações de 1 a 7 .

$$
\begin{aligned}
& Y_{i r}: \sum_{f} v f m_{f i r}+\sum_{j}\left(v i f m_{j i r}+v i f m_{j i r}\right)+R_{i r}^{\gamma}=v o m_{i r} \\
& M_{i r}: \sum_{S}\left[v x m d_{i s r}+\sum_{j} v t w r_{j i r s}\right]+R_{i r}^{M}=v i m_{i r} \\
& C_{r}: \sum_{i}\left(v d p m_{i r}+v i p m_{i r}\right)+R_{i r}^{C}=v p m_{r} \\
& G_{r}: \sum_{i}\left(v d g m_{i r}+v i g m_{i r}\right)+R_{i r}^{G}=v g m_{r} \\
& I_{r}: \sum_{i} v \operatorname{dim}_{i r}=v i m_{r} \\
& F T_{f r}: \operatorname{evom}_{f r}=\sum_{i} v f m_{f i r} \quad f \in s \\
& Y T_{j}: \sum_{i} v s t_{j r}=v t=\sum_{i r s} v t w r_{j i r s}
\end{aligned}
$$

Sendo respeitadas as condições de equilíbrio de mercado, os setores produtivos maximizam seus lucros.
Para isso, primeiramente, os setores devem minimizar os custos dada a restrição tecnológica de cada setor. Logo, o nível de produção Yir é caracterizado pela seleção dos insumos que, no total, apresentem um menor custo unitário.

A partir destas definições e considerando o objetivo de avaliar os potenciais impactos de incentivos à produção de leite no mercado brasileiro, formulou-se a agregação para analisar o setor de leite e derivados, desagregado no Paeg, aplicado às cinco regiões brasileiras, além dos principais exportadores ao Brasil, conforme Tabela 1.

Quanto ao fechamento do modelo, Gurgel et al. (2014) mencionam que existem alguns aspectos a serem considerados, quais sejam: (i) a oferta total de cada fator de produção não se altera, porém, pode ser alocada dentro dos diversos fatores; (ii) o fator terra é exclusivo aos setores agropecuários, enquanto recursos naturais são específicos aos setores de extração de recursos minerais e energia; (iii) não se admite desemprego no modelo, portanto os preços dos fatores são flexíveis e (iv) pelo lado da demanda, investimentos e fluxos de capitais são considerados fixos, da mesma forma que a balança de pagamentos; por isso, alterações na taxa de câmbio são necessárias para que importações e exportações continuem em equilíbrio.

Considerando essa agregação, na seção seguinte são expostos os cenários propostos a partir de alterações nos parâmetros de produção, tarifários e de comercialização do setor de produtos lácteos. Ressaltando que às simulações realizadas foram utilizados apenas os setores têm influência no setor lácteo. Já as desagregações dos países justifica-se pela participação do Brasil no mercado internacional. Em 2014 o País ocupou o

Tabela 1. Agregação entre regiões brasileiras e setores utilizados no modelo

\begin{tabular}{ll}
\hline \multicolumn{1}{c}{ Regiões } & \multicolumn{1}{c}{ Setores } \\
\hline 1 - Brasil - Região Norte (NOR) & 1 - Leite e derivados (rmk) \\
2 - Brasil - Região Nordeste (NDE) & 2 - Arroz (pdr) \\
3 - Brasil - Região Centro-Oeste (COE) & 3 - Milho e outros cereais em grãos (gro) \\
4 - Brasil - Região Sudeste (SDE) & 4 - Cana-de-açúcar, beterraba, açúc., ind. açúcar (c_b) \\
5 - Brasil - Região Sul (SUL) & 5 - Carnes e animais vivos (oap) \\
6- Resto do Mercosul (MER) & 6 - Outros produtos agropecuários (agr) \\
7 - União Europeia 15 (EUR) & \\
8- China (CHN) & \\
9 - Resto do Mundo (ROW) & \\
\hline
\end{tabular}

Fonte: Elaborado pelos autores (2016). 
quinto lugar no ranking das economias com maior produção de leite, atrás da União Europeia, Índia, Estados Unidos e China (USDA, 2014).

\subsection{Cenários de análise}

O setor agrícola brasileiro necessita de intervenção governamental devido as suas características biológicas e dada a incidência dos impostos no mercado doméstico, conforme Cardoso (2011). Assim sendo, devido às altas taxas de juros praticadas pelas agências distribuidoras de crédito, muitos produtores rurais não conseguem se inserir e se manter no mercado lácteo, necessitando de uma intervenção governamental, implementando políticas de subsídios por meio de programas de crédito e equalização da taxa de juros destes empréstimos.

Neste sentido, o Mapa, em 2012, criou o Programa Mais Pecuária, tendo como objetivo aumentar a produção de leite em $40 \%$ nos próximos dez anos, a partir de 2014. Como diretrizes, o programa conta com melhoramento genético, visando melhorar a produtividade por animal; ampliação de mercados; incorporação de novas tecnologias na atividade; investimentos em segurança e qualidade do leite in natura que serve como base para os derivados, a fim de ter mais visibilidade no mercado externo.

Quanto à equalização da taxa de juros (ETJ), seria uma das formas de subsidiar a produção agropecuária que, ao longo dos anos, tem contribuído à expansão da produção, como também a demanda por implementos agrícolas. Esta equalização consiste em subsidiar a diferença de taxas entre o custo de captação dos recursos pelas instituições financeiras e oficiais, acrescido dos custos administrativos e tributários dessas instituições e os encargos cobrados do tomador final do crédito. Com isso, o governo ampliaria, de forma compulsória, a participação dos bancos privados no financiamento do setor rural, aumentando a oferta de crédito (CARDOSO et al., 2011). Medida que for- neceria mais condições para o investimento na produção leiteira, já que os custos de produção têm crescido sistematicamente.

A produção de leite tem apresentado custos cada vez mais elevados, que se devem a necessidade de produzir alimentação rica em nutrientes para fornecer aos animais, como sementes, adubos e tratamento para o plantio de pastagens e a confecção de silagens para complementação alimentar. Estes últimos têm grande participação no dispêndio financeiro dos produtores rurais, além de serem acrescidos dos impostos de produtos primários. Ademais, os suplementos minerais vêm ganhando espaço na alimentação animal principalmente nos períodos com baixos volumes de chuva (CEPEA/LEITE, 2015).

A partir destas discussões, no Quadro 1, podem ser observados os dois cenários propostos com alterações nos subsídios e nos impostos, a fim de que se possa identificar alternativas para o aumento de produção de leite no Brasil.

O cenário 1 está ligado ao fornecimento de subsídios à produção do setor de lácteos brasileiro. Destaca-se que o Brasil não subsidia à produção de leite, apenas tem-se a concessão de financiamentos pelas empresas concessoras de crédito e de fomento da agricultura. Como base para este cenário, foram propostos aumentos de forma arbitrária de $10 \%$ e $20 \%$ da concessão de subsídios à produção de leite e derivados. A base deste cenário está nos efeitos que a ampliação na concessão de crédito rural e/ou redução dos juros pode exercer sobre a produção leiteira, bem como sobre os fluxos comerciais regionais e externos.

O cenário 2 trata dos impostos ao uso de fatores primários na produção. Sendo assim, a alteração proposta consiste na redução gradual nesta alíquota. Para tanto, são definidas duas faixas redutoras, de $10 \%$ e $20 \%$, a partir das alíquotas vigentes. Estes redutores tem o objetivo de verificar os efeitos, o comportamento da produção de lácteos, além da sensibilidade da produção a estes custos.

Quadro 1. Cenários de análise

\begin{tabular}{|l|l|l|}
\hline \multirow{2}{*}{ Cenários } & \multicolumn{2}{c|}{ Alterações } \\
\cline { 2 - 3 } & \multicolumn{1}{c|}{ Proposta 1 } & \multicolumn{1}{c|}{ Proposta 2 } \\
\hline 1 - Subsídios domésticos de produção & Aumento de 10\% (1A) & Aumento de 20\% (2A) \\
\hline 2 - Impostos ao uso de fatores primários na produção & Redução de 10\% (1B) & Redução de 20\% (2B) \\
\hline
\end{tabular}

Fonte: Elaborado pelos autores (2016). 
Ressalta-se que o setor de produtos lácteos possui uma carga tributária complexa que, junto a outros fatores endógenos, influenciam na elevação nos custos de produção da atividade, conforme discutem Lisboa e Latif (2013). Além disso, recentemente, em 2012, foi determinada a proibição do uso do crédito presumido para produtos lácteos que são isentos das alíquotas de PIS e Cofins. Segundo Pereira (2011), uma desoneração fiscal incentiva os níveis de produção, não apenas na produção agrícola, como em todos os setores da economia.

Os efeitos desta incidência de impostos no setor de lácteos, inicialmente, seriam a geração de dois preços distintos: aquele recebido pelo produtor e o preço pago pelo consumidor, sendo a diferença entre os dois, o imposto. Neste caso, para o setor lácteo, a imposição de um imposto seria prejudicial, já que esse setor possui uma demanda inelástica e haveria um aumento de custos para o produtor. Assim, a curva de oferta se desloca em uma proporção maior em relação à quantidade que será ofertada, enquanto que a demanda terá poucas alterações (BRUNOZI JÚNIOR et al., 2012).

No Brasil, embora os subsídios diretos não sejam aplicados, indiretamente são utilizados mecanismos compensatórios, caso do crédito rural concedido com condições diferenciadas, a partir do qual os produtores podem obter recursos financeiros para intensificar a produção a juros mais baixos do que aqueles praticados pelo mercado. Outra forma, de acordo com Cardoso e Teixeira (2013), está na prestação de serviços de pesquisa e extensão, treinamento e desenvolvimento da infraestrutura rural, a cargo das empresas públicas especializadas em apoio técnico (Embrapa, Senar, Emater).

\section{Resultados e discussões}

\subsection{Análise das variações nos níveis de produção}

Inicialmente são analisadas as variações na produção brasileira de leite e derivados considerando os dois cenários propostos. O cenário 1 apresenta as propostas de aumento em $10 \%$ e $20 \%$ na concessão de subsídios à produção de leite e derivados (cenários $1 \mathrm{~A}$ e $2 \mathrm{~A})$, enquanto que o cenário 2 , reduções de $10 \%$ e $20 \%$ nos impostos ao uso de fatores primários na produ- ção (cenários 2A e 2B). Ressaltando que as simulações foram realizadas a partir do cenário base e os choques realizados nos níveis de subsídios e impostos praticados no setor de lácteos brasileiro (ver Anexo).

Considerando um aumento na concessão de subsídios à produção de 10\%, na forma de ampliação do financiamento e/ou redução dos juros, conforme cenário $1 \mathrm{~A}$, observa-se que a produção se expande nas regiões Sudeste e Sul, enquanto as demais apresentam redução. A região que apresentou maior resultado positivo foi a Sudeste, com aumento de $0,14 \%$ na produção, seguido da região Sul, cujo aumento foi de $0,08 \%$. Ambas as regiões são as principais produtoras brasileiras de leite, sendo que, conjuntamente, produzem cerca de dois terços da produção total (Tabela 2).

Decorrente deste crescimento, também se observam resultados positivos nos produtos agrícolas que possuem atividade atrelada a produção de leite, caso do milho, trigo, animais vivos, soja, outros alimentos, com exceção do arroz, que apresentou queda de 0,02\% na região SDE, porém, crescimento de $0,05 \%$ na Sul. Estas variações positivas, entendidas como efeitos indiretos, podem ser explicadas pela expressiva utilização destes produtos na alimentação dos bovinos. Salman, Osmari, Santos (2010) complementam, expondo que os custos com alimentação do rebanho compreendem entre $40 \%$ e $60 \%$ dos custos totais de produção na atividade leiteira e dependem da disponibilidade dos outros produtos agrícolas (soja, trigo, milho, cana-de-açúcar) para aumentar a produção.

Nestes termos, o aumento na concessão de subsídios à produção de leite e derivados, na forma de maior disponibilidade de crédito ou menores taxas de juros, faria com que os investimentos fossem ampliados, bem como a produção do setor. Além disso, embora a produção de leite seja uma atividade rentável, possui um alto custo de entrada, com os produtores necessitando de um elevado investimento inicial para o desempenho da atividade, portanto, maior disponibilidade de crédito ou um menor custo de financiamento estimularia os produtores a investir na atividade leiteira (CEPEA, 2011).

Já nas regiões Norte, Nordeste e Centro-Oeste, o aumento dos subsídios em $10 \%$ reduziu a produção de leite e derivados, em maior magnitude na NDE $(-0,24 \%)$. Isso pode ser explicado pela mobilidade de fatores, que tendem a se deslocar para as regiões mais produtivas, havendo com isso déficit de mão de obra 
e de capital nestas regiões. Além disso, tais resultados indicam que a produção de leite é pouco sensível a maiores volumes de crédito rural nessas referidas regiões, situação que pode estar ligada também a outras questões, como condições climáticas e temperatura.

Porém, essas evidências vão de encontro aos resultados de Cardoso (2011), que encontrou que, em decorrência dos gastos com a equalização da taxa de juros e do volume de crédito rural disponibilizado, a produção de leite e derivados elevou-se também nas regiões Norte, Nordeste e Centro-Oeste. Justificado pelo fato de que as atividades agropecuárias nestas regiões possuem vantagens comparativas em relação à indústria.

Na segunda situação proposta, no cenário $2 \mathrm{~A}$, que consistiu na redução de $10 \%$ nos impostos ao uso de fatores primários na produção, considerando mudanças na alíquota de tributação, observa-se aumento na produção de leite e derivados nas regiões SDE e COE, com variação mais significativa na região sudeste $(0,05 \%)$. As demais regiões apresentaram queda na produção, com destaque à região norte, cuja queda foi de $0,21 \%$. Estes efeitos podem ser explicados pela livre mobilidade de fatores entre as regiões brasileiras, o que, segundo Souza (2005), determina que os fatores de produção (capital e trabalho) tendem a se deslocar de regiões com baixos rendimentos para aquelas onde há mais produtividade e melhores salários, até que uma nova condição de equilíbrio de mercado seja atingida.

Por sua vez, estas evidências diferem parcialmente dos achados de Pereira (2011), quando analisou os efeitos da Rodada Doha e das políticas de desoneração tributária nas regiões brasileiras. À redução de $10 \%$ nas alíquotas de tributos indiretos que incidem sobre a economia brasileira foram encontrados efeitos positivos à produção em todas as regiões, com exceção da região Nnordeste. A maior variação foi identificada na região Norte $(3,38 \%)$, seguida da região Sudeste $(2,75 \%)$. Tais variações indicaram que a redução de impostos é mais eficaz à competitividade da indústria, sendo que menos recursos são deslocados da indústria à agricultura com uma desoneração fiscal.

Da mesma forma que o encontrado para o cenário $1 \mathrm{~A}$, a redução dos impostos primários à produção de leite e derivados expande a demanda dos demais produtos utilizados na atividade leiteira. Crescimento esse que pode ser explicado pelo fato de o setor depender principalmente de outros produtos agrícolas para o fornecimento da alimentação para os animais. Logo, a diminuição nos impostos reduziria os custos de produção ao mesmo tempo em que incentivaria os produtores a aumentar a produtividade pela utilização de mais insumos à produção (CEPEA/LEITE, 2015).

As alterações dos níveis de produção do primeiro cenário, de expansão de $20 \%$ na concessão de subsídios à produção e, do segundo, de redução de $20 \%$ nos custos primários, estão expostas na parte inferior da Tabela 2. De forma geral, verifica-se que, com propostas mais expressivas em termos de aumento de subsídios (1B) e de redução nos impostos ao uso de fatores primários na produção (2B), as variações observadas também foram mais significativas quando comparadas aos primeiros cenários (1A e 2A).

Os movimentos em termos de produção regional foram similares, com a região sudeste apresentando a maior variação positiva na produção de leite e derivados, expansão de $0,28 \%$, seguido da região sul, cuja variação positiva foi de $0,17 \%$. Resultado que sugere que, quanto maior a concessão de subsídios ao setor de leite e derivados, maior será o nível de produção observado, porém, apenas nas regiões mais produtoras. Consequentemente, depreende-se que políticas homogêneas para o setor lácteo tenderão a gerar concentração na produção nas regiões de maior produtividade.

Essas duas regiões apresentam estruturas produtivas bem formadas, investimentos em genética e alimentação, além de programas de qualidade que auxiliam o produtor a investir na atividade favorecendo o aumento do valor nutricional do leite in natura produzido, com isso ganhando em termos de produtividade. Aspectos esses que fazem com que as regiões Sul e Sudeste apresentem os maiores índices de produtividade dentre as regiões brasileiras, embora não apresentem os maiores rebanhos (REZENDE, 2011).

Seguindo a mesma tendência, em comparação com o cenário 1A, as regiões NOR, NDE e COE apresentaram quedas ainda maiores na produção de leite e derivados (rmk). Estes resultados negativos são justificados pelo fato de que, nestas regiões, a estrutura produtiva do setor é oposta aquelas observadas nas outras regiões brasileiras. O parque industrial ainda é muito restrito, fazendo com que apenas cerca de $30 \%$ do leite in natura seja processado e comercializado pelas indústrias (SEBRAE, 2013). Aspecto esse que acaba se refletindo nos preços recebidos pelos produtores, os quais estão entre os mais baixos do país (CEPEA/LEITE, 2015). 


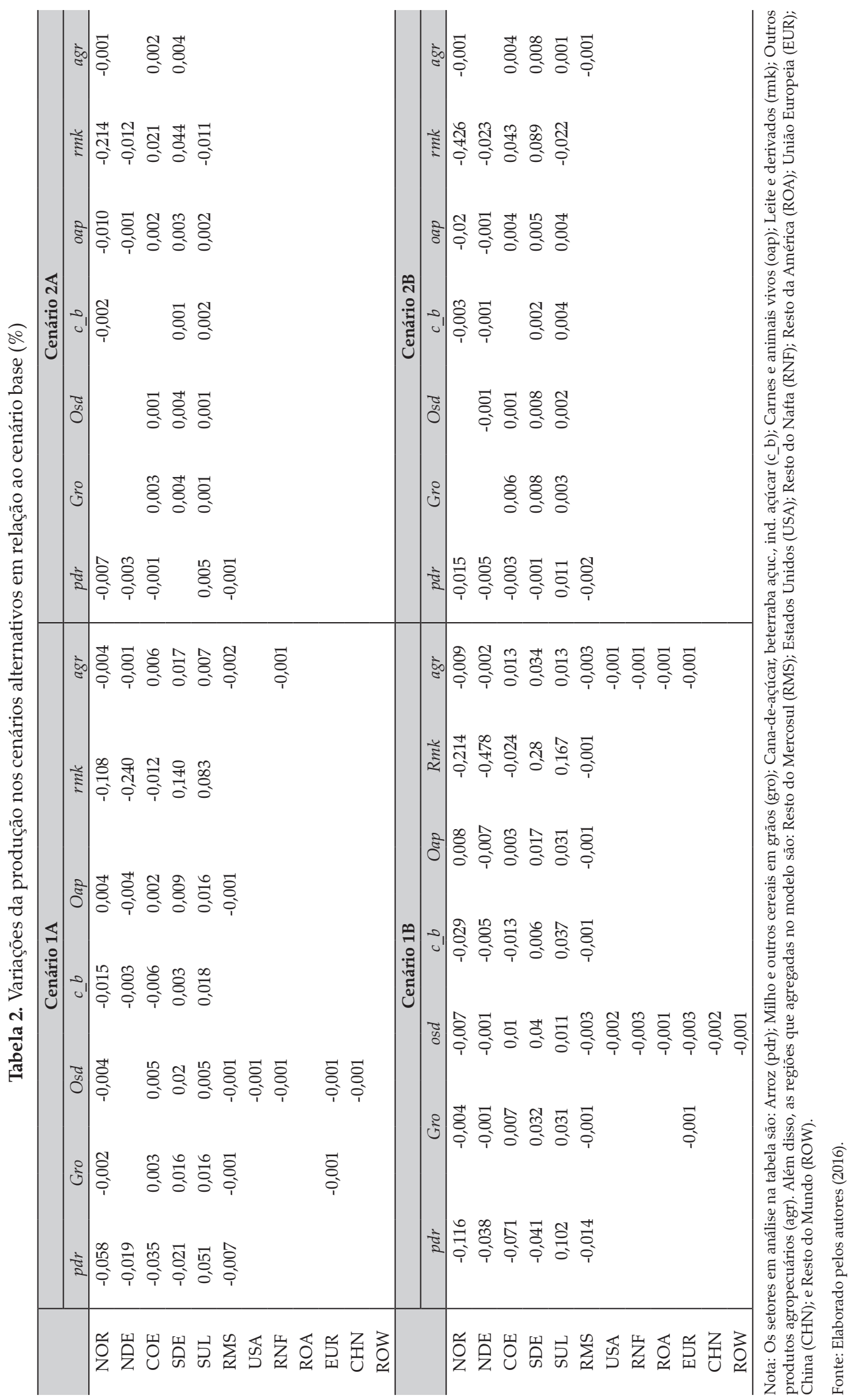


Quanto ao cenário 2B, em que foi simulada uma redução de $20 \%$ nos impostos ao uso de fatores primários na produção de leite e derivados, verifica-se o mesmo comportamento do cenário $2 \mathrm{~A}$, com variações mais significativas. As regiões Sudeste e Centro-Oeste apresentaram as maiores variações positivas nos níveis de produção - 0,09\% e 0,04\%, respectivamente. Expansão que pode estar ligada aos estados de Goiás e Minas Gerais, que apresentam os maiores custos totais de produção.

Ressalta-se que o estado mineiro, principal produtor de leite da região sudeste apresentou variação mensal no índice de custos totais da produção de leite de 0,81\% no período de 2010 a 2015, maior variação dentre todos os estados analisados pelo Cepea/Leite (2015). Igualmente, o estado de Goiás, maior produtor de leite da região Centro-Oeste, apresentou a segunda maior variação mensal no índice de custos totais da produção de leite, de $0,80 \%$. Logo, evidencia-se que os custos mais elevados de produção do leite mostraram-se mais sensíveis às mudanças nos impostos ao uso de fatores primários, refletindo-se consequentemente em um maior aumento na produção do setor.

Nas outras regiões, a redução de $20 \%$ nos impostos ao uso de fatores primários provocou queda na produção de leite e derivados, inclusive na região SUL $(0,02 \%)$, além da região $\mathrm{NOR}$, cuja retração foi mais expressiva (0,43\%). Quanto à Sul, os resultados podem ser justificados pelo fato de a região possuir grande número de propriedades familiares exercendo a atividade, as quais possuem uma estrutura de custos mais enxuta. Neste caso, a desoneração fiscal não seria tão eficaz quanto um aumento na disponibilidade de crédito ou equalização da taxa de juros, propostas dos cenários $1 \mathrm{~A}$ e $1 \mathrm{~B}$.

Em síntese, com relação à produção de leite e derivados, os cenários simulados indicam que ocorreram variações, ainda que de diferentes magnitudes, em todas as regiões brasileiras, principalmente para aquelas mais intensivas na produção de leite in natura, caso das regiões Sul e Sudeste. Já nas regiões com menor participação na produção, as reduções foram maiores quanto maior o volume de subsídios e menores os custos de produção.

Esse resultado reflete o diferencial de produtividade entre as regiões; já para as regiões exportadoras de leite para o mercado brasileiro, as propostas simuladas não resultaram em alterações nos respectivos níveis de produção de leite e derivados. Com relação às exportações, dois aspectos devem ser considerados, que seriam a ausência de alterações nos níveis de produção às regiões exportadoras. Determinado principalmente pelo fato de que mudanças no cenário externo devem-se, em grande medida, a ganhos de produtividade e devido à participação brasileira nas exportações de lácteos, que é muito pequena.

\subsection{Análise das variações dos preços domésticos}

Da mesma forma que na análise anterior, o cenário 1 apresenta duas propostas, de aumento de $10 \%$ e $20 \%$ na concessão de subsídios à produção de leite e derivados (cenário $1 \mathrm{~A}$ e $1 \mathrm{~B}$, respectivamente) e, de redução em $10 \%$ e $20 \%$ nos impostos ao uso de fatores primários (cenário $2 \mathrm{~A}$ e $2 \mathrm{~B}$ ). Porém, neste ponto são analisadas as variações nos preços domésticos do leite e derivados (rmk), bem como nos preços das commodities que têm influência na produção do setor lácteo.

Considerando o cenário $1 \mathrm{~A}$, verificou-se queda, ainda que marginal, nos preços domésticos de leite e derivados em todas as regiões brasileiras, o que se explica pela maior oferta doméstica do produto, sobremaneira nas regiões Sudeste e Sul. Em termos regionais, os preços domésticos do leite e derivados no Sudeste apresentaram a maior variação negativa, de 0,32\%, enquanto que a região Nordeste apresentou a menor queda, com variação praticamente nula (ver Tabela 3). Mesma tendência de retração é observada para os preços externos; porém, enquanto nas regiões brasileiras a média de queda ficou em torno de $0,28 \%$, para as regiões exportadoras as mudanças foram reduzidas.

As outras regiões também apresentam comportamento similar, ressaltando que os níveis mais elevados de queda de preços do leite e derivado são observados, depois da região Sudeste, foram na região Sul (0,30\%), na região Centro-Oeste $(0,25 \%)$ e também a região Norte $(0,22 \%)$. Conforme discutido, dadas às alterações na produção do setor, a maior oferta impulsionada pelo aumento de subsídios, provocam alterações negativas nos preços, entretanto em amplitudes diferentes em cada uma das regiões brasileiras.

Estas variações resultam em grande parte de como os preços são formados nas respectivas regiões. Nesta mesma linha, Carvalho et al. (2013) encontraram que o estado de Minas Gerais, que é o maior produtor de 


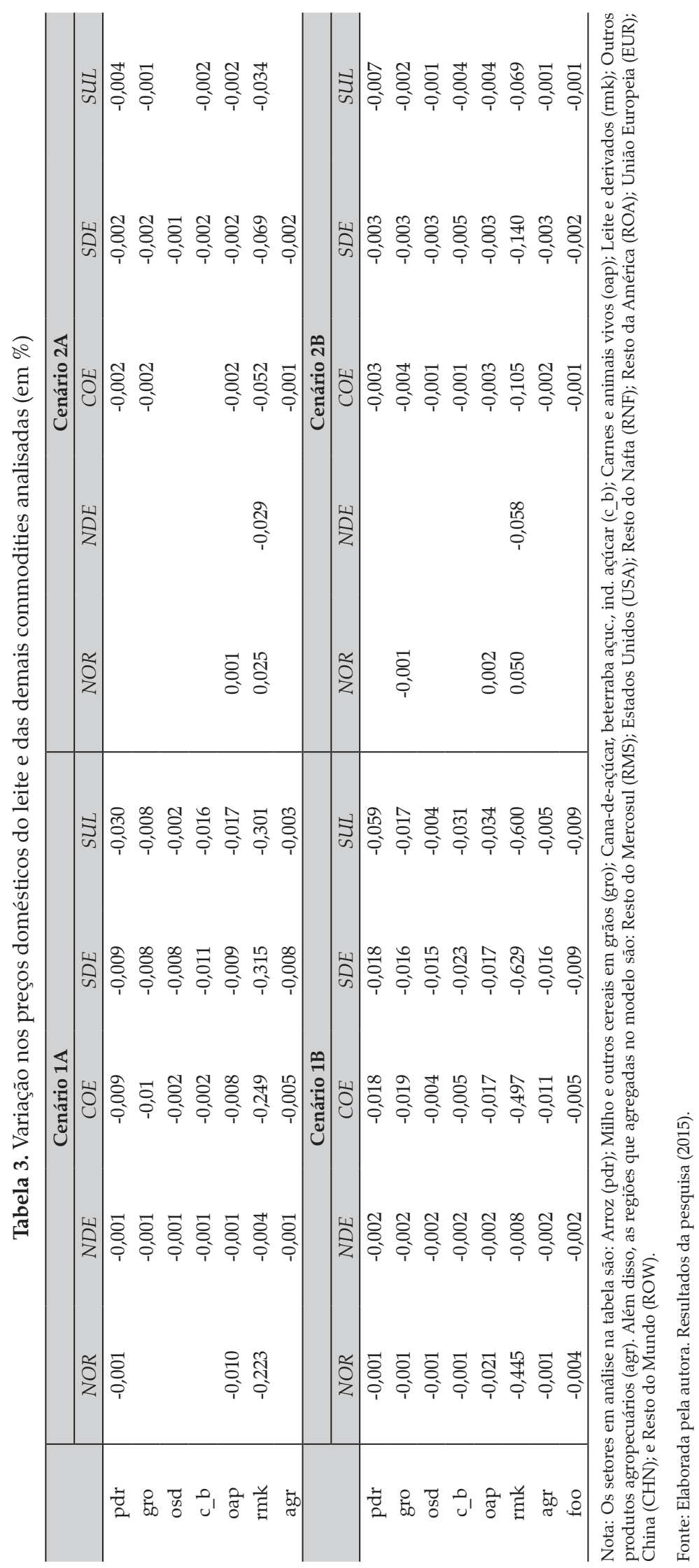


leite da região Sudeste, é o principal formador de preço pago ao produtor pelo leite in natura, seguido do estado de São Paulo, enquanto que Goiás, estado com maior participação na produção de leite in natura da região Centro-Oeste apresentou características de tomador de preços. Além disso, os estados do Rio Grande do Sul e Paraná têm mais influência dos seus próprios preços do que dos praticados pelos estados do Sudeste.

No que tange aos preços domésticos e externos dos outros produtos agrícolas, também observaram-se alterações, visto que parte da produção destas commodities é utilizada como insumo na produção de leite in natura. Este efeito ocorre pelo fato de que o maior volume de crédito rural e/ou a política de equalização da taxa de juros provoca efeitos indiretos nos preços dos produtos praticados, dado que altera os preços relativos e a demanda por outros bens e serviços.

Já quando considerados níveis mais elevados de concessão de subsídios à produção de leite e derivados, caso do cenário $1 \mathrm{~B}$, observa-se comportamento similar àquele exposto no cenário 1A. Destacando-se a queda nos preços, principalmente nas regióes Sudeste e Sul. Resultados análogos aos obtidos por Cardoso e Teixeira (2011), quando avaliaram o impacto da equalização da taxa de juros do crédito rural em 2004 sobre os preços domésticos e importados dos principais produtos brasileiros. Nesta situação, o preço de leite e derivados apresentou queda tanto para os preços praticados no mercado interno como também no externo.

No cenário $2 \mathrm{~A}$, em que é simulada a redução de $10 \%$ nos impostos ao uso de fatores primário na produção, obteve-se redução nos preços pagos para todas as regiões, com exceção da Norte, que apresentou elevação nos preços ainda que marginal $(0,03 \%)$. Isso justifica-se pelas alterações negativas encontradas na produção $(0,21 \%)$. Neste caso, a diminuição da oferta destes produtos determinou o aumento nos preços. Ademais, essa região possui características peculiares na atividade leiteira, sendo observado um grande número de produtores que realizam a atividade basicamente à subsistência, não contando com mão de obra qualificada na produção. Embora tenham auxílio técnico de órgãos governamentais, os produtores não têm a cultura cooperativista e associativista, assim, não conseguem poder de barganha com relação a preços, tanto para o leite comercializado, quanto para os insumos utilizados na produção (SOUZA, AMIN e GOMES, 2009).
Já os resultados à região NDE indicam que, ao mesmo tempo em que apresentou queda na produção de leite e derivados (resultados dos cenários 1A e 1B), também apresentou retração nos preços domésticos dos produtos do setor em ambas as simulações. Em linha com a Embrapa (2015), quando expõe que a região Nordeste apresenta aporte tecnológico deficitário, induzindo a utilização de áreas maiores à atividade, afastando as unidades produtoras dos centros consumidores, onde estão localizadas as agroindústrias e empresas beneficiadoras, influenciando na produção e nos preços recebidos pelos produtores.

Resumindo, com exceção da região Norte, as demais tiveram influência da queda de preços domésticos observados no Sudeste, visto que é formador de preços no mercado lácteo brasileiro. Outro fator decisivo à queda nos preços, dado o cenário de aumento de subsídios, relacionou-se ao aumento na produção das regiões Sudeste e Sul, que apresentam o maior volume de produção de leite in natura.

$\mathrm{O}$ mesmo é observado no cenário $2 \mathrm{~B}$, quando simulou-se uma redução de $20 \%$ nos impostos ao uso de fatores primários na produção de leite e derivados, porém em magnitudes mais significativas quando comparado com a redução simulada no cenário $2 \mathrm{~A}$. Depreende-se com isso, que as regiões sudeste e centro-oeste mostraram-se mais sensíveis as reduções nos custos de produção.

Todavia, os preços domésticos de leite e derivados tiveram maior influência na simulação dos cenários $1 \mathrm{~A}$ e $1 \mathrm{~B}$, quando foram concedidos aumentos de subsídios à produção, comparativamente aos cenários de redução de impostos. Neste caso, com aumento de subsídios, os preços praticados nas regiões brasileiras apresentaram variações negativas mais expressivas do que aquelas observadas com a redução de impostos.

\section{Conclusões}

A expansão da agropecuária brasileira na década de 1970 impulsionou o desenvolvimento da atividade leiteira nas regiões brasileiras. Neste período, a estrutura produtiva era pouco desenvolvida e contava com um número reduzido de empresas responsáveis por beneficiar o leite in natura e comercializar os derivados lácteos. Porém, com a abertura comercial ocorrida nos anos 1990, o cenário econômico do setor teve grandes 
alterações com a entrada de empresas multinacionais atuando na produção de derivados e também introduzindo novas formas de produzir e comercializar o leite in natura. As empresas Parmalat e Danone trouxeram para o mercado brasileiro a ultrapasteurização, além de vários outros derivados do leite que ainda não eram comercializados domesticamente.

Nos anos mais recentes, a produção de leite no Brasil tem sido realizada de diferentes formas em cada uma das regiões, sendo que na Sudeste, Sul e Centro-Oeste empregam-se mais tecnologias para o desenvolvimento da atividade quando comparada as demais regiões. Todavia, em todas elas observou-se um aumento na produção, quando considerado o período entre 1998 e 2014, inclusive com expansão no número de produtores, porém, ainda insuficiente para atender à demanda doméstica.

Considerando-se este contexto, objetivou-se avaliar os potenciais impactos de estímulos à produção de leite nas regiões brasileiras a partir das políticas de estímulo à produção. Para atender tal objetivo, foram simulados dois cenários, cada um composto de duas propostas: o primeiro de aumento de $10 \%$ e $20 \%$ na concessão de subsídios à produção de leite e derivados, enquanto que a segunda, de redução de 10\% e 20\% nos impostos ao uso de fatores primário na produção de leite e derivados. Para simular tais alterações bem como analisar os impactos gerados foi utilizado o Programa de Equilíbrio Geral da Economia Brasileira (Paeg).

De forma ampla, evidenciou-se que a região Sudeste, a de maior representatividade na produção de leite in natura, seria a que maior impacto na produção de leite e derivados apresentaria quando simuladas as propostas de ampliação de subsídios, seja na forma de crédito ou equalização da taxa de juros. $\mathrm{O}$ mesmo ocorreu com a região Sul, que expandiu a produção com a concessão de subsídios. De outra forma, nas regiões Norte, Nordeste e Centro-Oeste, regiões com menor representatividade na produção total, bem como na produtividade, o efeito foi marginal. A partir disto, conclui-se que uma política de concessão de subsídios, de caráter homogêneo, seria eficaz para aumentar a produção, porém, o crescimento ocorreria apenas nas regiões que já são importantes produtoras. Além disso, esta política tenderia a ampliar a concentração da produção de leite e derivados.

Considerando política de redução nos impostos ao uso de fatores primários na produção de leite e deri- vados, da mesma forma, a região Sudeste ampliaria seu volume de produção, sendo o mesmo efeito verificado na região Centro-Oeste. Diferente do primeiro cenário, além das regiões Norte e Nordeste, a região Sul apresentou queda na produção, mesmo sendo uma das principais produtoras e tendo os maiores níveis de produtividade.

A partir destes resultados, conclui-se que o aumento da produção nas diferentes regiões ocorreria a partir da adoção de políticas regionais e setoriais diferenciadas. Do contrário, a produção concentrar-se-ia nas regiões mais eficientes, acentuando as diferenças produtivas. Além de abrir espaço para a entrada do produto externo, cujas condições de mercado, em grande medida, são favoráveis. Neste caso, foi constatado que um aumento na concessão de subsídios à produção de leite e derivados teria maior impacto na produção se comparado ao cenário de redução de impostos.

Embora os resultados tenham mostrado tendências importantes para o aumento da produção de leite e derivados, alguns pontos limitantes devem ser mencionados, caso da agregação do setor, impossibilitando de ser realizada uma análise separada do mercado de leite in natura do de derivados. Ademais, a indisponibilidade de dados da produção de derivados lácteos não possibilitou melhor contextualização deste mercado. A partir disto, sugere-se que sejam estudadas outras formas de incentivos à produção, em específico aquelas voltadas ao aumento da produtividade, como também programas de pagamento por qualidade para que o mercado de lácteos brasileiro possa expandir-se de forma sustentada e, com isso, reduzir a redução da dependência externa do País.

\section{Referências}

ASSOCIAÇÃO Brasileira dos Produtores de Leite. Produção mundial de lácteos. 2014. Disponível em: $<$ http://www.leitebrasil.org.br/>. Acesso em: mar. 2015.

BORGES, M. S. et al. Modernização, Trabalho e Produtividade na Pequena Produção Leiteira na Argentina e no Brasil. Revista ADM.MADE, Rio de Janeiro, ano 14, v. 18, n. 1, p. 12-31, jan./abr. 2014.

BORTOLETO, E. e WILKINSON, J. Competitividade, inovação e demandas tecnológicas no sistema 
agroindustrial do Mercosul ampliado - lácteos. Anais... CONGRESSO BRASILEIRO DE ECONOMIA E SOCIOLOGIA RURAL, 38., 2000, Rio de Janeiro-RJ. Anais. SOBER, 2000.

BROOKE, A. et al. GAMS: a user's guide. GAMS Development Corporation, 1988.

BRUNOZI JÚNIOR, A. C. et al. Mercado e tributação: uma abordagem teórica sob a perspectiva de estruturas de mercado na cadeia agroindustrial do leite. Documentos Técnico-Científicos, v. 43, n. 1, jan./mar. 2012.

CARDOSO, D. F. Efeitos da política de equalização das taxas de juros do crédito rural no crescimento econômico das regiões brasileiras. Dissertação (Mestrado em Economia Aplicada) - Universidade Federal de Viçosa, 2011.

CARVALHO, B. H. P. et al. Integração intra e intermercado: o caso dos preços do leite e derivados no Brasil. Anais... Encontro Nacional de Pesquisadores em Economia. Anis ANPEC, Foz do Iguaçú (PR), 2013.

CENTRO de Estudos Avançados em Economia Aplicada. Boletim do Leite. In: CEPEA Leite, ESALQ/ USP. Ano 10, n. 106, jan. 2003.

. Boletim do Leite. In: CEPEA Leite, ESALQ/USP. Ano 15, n. 176, abr. 2009.

. Boletim do Leite. In: CEPEA Leite, ESALQ/USP. Ano 20, n. 233, set. 2014.

. Boletim do Leite. In: CEPEA Leite, ESALQ/USP. Ano 21, n. 237, jan. 2015.

DEPARTAMENTO Intersindical de Estatística e Estudos Socioeconômicos - DIEESE. Alimentos ainda pressionam o custo de vida em São Paulo. Nota à imprensa, dez. 2014. Disponível em: <http://www. dieese.org.br/analiseicv/2014/201411analiseicv.pdf $>$. Acesso em: fev. 2015.

EMPRESA Brasileira de Pesquisa Agropecuária. Embrapa Gado de Leite. Sistemas de Produção. Disponível em: <http://www.cnpgl.embrapa.br/ sistemaproducao/>. Acesso em: fev. 2015.

- Agência de Informação Embrapa, Agronegócio do Leite, 2013. Disponível em: <http://www. agencia.cnptia.embrapa.br/Agencia8/AG01/arvore/ AG01_26_217200392357.html>. Acesso em: mar. 2015.

- Desafios para a produção de leite no Nordeste. Artigos, 2015. Disponível em: < https://www.embrapa. br/busca-de-noticias/-/noticia/2697798/artigo-desafiospara-a-producao-de-leite-no-nordeste $>$. Acesso em: jan. 2016.

GOMES, S. T. Analise da economia leiteira brasileira. Artigos técnicos. Universidade Federal de Viçosa, 1995.
Disponível em: <http://www.ufv.br/der/docentes/stg/ stg_artigos/Art_085\%20-\%20AN\%C1LISE\%20DA\% 20 ECONOMIA \% 20LEITEIRA \% 20BRASILEIRA \% 20 \%2819-1-95\%29.pdf>. Acesso em: fev. 2015.

GURGEL, A. C., PEREIRA, M. W. G. e TEIXEIRA, E. C. Programa de Equilíbrio Geral da Economia Brasileira - PAEG. Técnica Papear No. 1. Versão dezembro 2014. Disponível em: <http://www.paeg.ufv.br/?page_ id=11>. Acesso em: jan. 2015.

HERTEL, T. W. Global Trade analysis: modeling and applications. New Yourk: Cambridge University Press, 1997.

INSTITUTO Brasileiro de Geografia e Estatística IBGE. Sistema de Recuperação Automática - Banco de dados. Disponível em: <http:/www.sidra.ibge.gov.br/bda/ tabela/protabl.asp?c $=1086 \& \mathrm{z}=\mathrm{t} \& \mathrm{o}=24 \& \mathrm{i}=\mathrm{P}>$. Acesso em: jan. 2015.

. Estatística da Produção Pecuária Setembro de 2014. Disponível em: <http://ibge.gov.br/home/estatistica/ indicadores/agropecuaria/producaoagropecuaria/ abate-leite-couro-ovos_201402_publ_completa.pdf $>$. Acesso em: fev. 2015.

. Pesquisa Trimestral do Leite, 2014. Disponível em: <http://www.ibge.gov.br/home/estatistica/pesquisas/ pesquisa_resultados.php?id_pesquisa $=43>$. Acesso em: fev. 2015.

População Brasileira, 2014. Disponível em: <http://www.ibge.gov.br/home/mapa_site/mapa_site. php\#populacao >. Acesso em: fev. 2015.

INSTITUTO de Pesquisa Econômica Aplicada (Ipea). Radar: tecnologia, produção e comércio exterior, 2014. Disponível em: <http://www.ipea.gov.br/portal/> . Acesso em: mar. 2015.

JANK, M. S., FARINA, E. M. Q. e GALAN, V. B. O agribusiness do leite no Brasil. São Paulo: Milkbizz, 1999.

LISBOA, M. B. e LATIF, Z. A. Democracy and growth in Brazil. INSPER. Instituto de Pesquisa e Ensino. Tradução: Francisco Marcos Macedo Salgado. Working Papers. São Paulo, 2013.

MINISTÉRIO da Agricultura, Pecuária e Abastecimento. Produção de leite conforma Instrução Normativa 62. Ministério da Agricultura, Pecuária e Abastecimento. Assessoria de Gestão Estratégica - Brasília: MAPA/ACS, 2006.

. Plano mais pecuária / Ministério da Agricultura,

Pecuária e Abastecimento. Assessoria de Gestão Estratégica. - Brasília: MAPA/ACS, 2014. 
MINISTÉRIO da Fazenda. Impostos sobre produtos alimentícios no Brasil. 2015. Disponível em: <http://idg. receita.fazenda.gov.br/> . Acesso em: mar 2015.

PARRÉ, J. L. O agronegócio nas macrorregiōes brasileiras: 1985 a 1995. Tese (Doutorado em Economia) - Escola Superior de Agricultura Luiz de Queiroz, Universidade de São Paulo. Piracicaba, 2000.

PEREIRA, M. W. G., TEIXEIRA, E. C. e GURGEL, A. C. Os custos do fracasso das negociações da Rodada de Doha para o setor lácteo nas regiões brasileiras. In: LEITE, J. L. B., SIQUEIRA, K. B. e CARVALHO, G. R. (Orgs.). Comércio internacional de lácteos. 2. ed. Juiz de Fora: Embrapa Gado de Leite, 2009, p. 203-232.

REZENDE, E. S. J. Instrução Normativa 51: adequação do leite cru em três mesorregióes de Minas Gerais. Dissertação (Mestrado em Ciência dos Alimentos) Universidade Federal de Lavras: UFLA, 2011.

RUTHERFORD, T. F. Applied general equilibrium modeling with MPSGE as a GAMS subsystem: na overview of the modeling framework and syntax. Computational Economics, v. 14, 1999.

. e PALTSEV, S. V. GTAPinGAMS and GTAP-EG: $\overline{\text { global }}$ database for econmic research and illustrative models. Boulder: Departamento f Economics University of Colorado, 2000.
. GTAPin GAMS: The dataset and statistic model. Prepared for the Workshop: "Alplied General Equilibrium Modeling for Trade Policy Analisys in Russia and the CIS". Moscow: The World Bank Resident Mission, dez. 2005.

SALMAN, A. K. D., OSMARI, E. K. e SANTOS, M. G. R. Manual prático para formulação de ração para vacas leiteiras. Porto Velho, RO: Embrapa Rondônia, 2011. 24 p. (Documentos / Embrapa Rondônia, ISSN 0103-9865, 145).

SOCIEDADE Nacional da Agricultura. Notícias. Consumo de lácteos perde fôlego no País. 2015. Disponível em: $\quad<$ http://sna.agr.br/consumo-de-lacteos-perdefolego-no-pais/>. Acesso em: jan. 2015.

SOUZA, E. L. L. e PIMENTEL, F. L. Study on Cédula de Produto Rural (CPR) - farm product bond in Brazil. Anais... Rural Finance Innovation Study. World Bank. Washington, 2005.

SOUZA, M. P., AMIN, M. M. e GOMES, S. T. Agronegócio leite: características da cadeia produtiva do estado de Rondônia. Revista de Administração e Negócios da Amazônia, v. 1, n. 1, mai./ago. 2009.

TEIXEIRA, E. C. et al. Projeto de Análise de Equilíbrio Geral da Economia Brasileira (PAEGBrasil). Relatório Técnico Final de Pesquisa CNPq. 2008. 63p. 
800 - Mercado Brasileiro de Lácteos: análise do impacto de políticas de estímulo à produção

\section{Anexo A}

Tabela 1A. Cenário base

\begin{tabular}{lcccccc}
\hline & Bs_C & Bs_G & Bs_I & Bs_X & Bs_M & Bs_PIB \\
\hline NOR & 32,14897 & 7,54258 & 21,96727 & 23,28226 & 24,47603 & 60,46505 \\
NDE & 90,07666 & 23,50555 & 45,43191 & 40,55581 & 44,99215 & 154,57778 \\
COE & 53,4532 & 17,79127 & 34,47272 & 28,60467 & 29,70136 & 104,6205 \\
SDE & 408,40209 & 103,60191 & 104,19083 & 200,65715 & 200,00484 & 616,84714 \\
SUL & 140,32215 & 30,35732 & 51,87764 & 141,32705 & 106,31233 & 257,57183 \\
NAF & 11433,565 & 2647,872 & 3236,2541 & 2053,5703 & 2743,4136 & 16627,848 \\
EUR & 9902,9253 & 3500,3757 & 3666,4895 & 5636,3976 & 5782,632 & 16923,556 \\
ROW & 11227,3 & 3162,0495 & 5682,0169 & 6744,1801 & 5937,0426 & 20878,503 \\
\hline
\end{tabular}

Os dados indicam: C: Private Consumption; G: Government Consumption; I: Investment; X: Exports; M: Imports; Bs: base data.

Fonte: Elaborado pelos autores com base nos dados do Paeg (2007).

Tabela 2A. Tributos e subsídios contidos no Paeg e utilizados como base para os choques das simulações

\begin{tabular}{cccccc}
\hline & NOR & NDE & COE & SDE & SUL \\
\hline rtf & 0,0645568 & 0,0645568 & 0,0645568 & 0,0645568 & 0,0645568 \\
rto & $-0,027396$ & $-0,0003185$ & $-0,0244669$ & $-0,0309898$ & $-0,0266537$ \\
\hline
\end{tabular}

Os dados indicam: rtf: Impostos ao uso de fatores primários na produção; rto: Subsídios à produção.

Fonte: Elaborado pelos autores com base nos dados do Paeg (2007). 